\title{
Janus-Cornarius-Lehrpreis an PD Dr. Martin Freesmeyer
}

PD Dr. Martin Freesmeyer, Chefarzt der Klinik für Nuklearmedizin am Uniklinikum Jena, ist mit dem Janus-Cornarius-Lehrpreis ausgezeichnet worden.

PD Dr. Freesmeyer erhielt den Preis gemeinsam mit seinem Kollegen Prof. Dr. Ulf Teichgräber, Direktor des Instituts für Diagnostische und Interventionelle Radiologie, stellvertretend für alle Lehrenden des Querschnittsbereichs Bildgebende Verfahren, Strahlenbehandlung und Strahlenschutz.

Mit dem Preis wurde insbesondere die Online-Lehre in dem durch die Corona-Pandemie beeinflussten Sommersemester ausgezeichnet. Die Lehr- und Lernvideos, Skripte und Übungsfragen seien übersichtlich, anschaulich und spannend aufbereitet gewesen, hieß es in der Begründung.

Der nach dem ersten Dekan der Medizinischen Fakultät an der Universität Jena - Janus Cornarius - benannte Preis wird jährlich von der Fachschaft Humanmedizin vergeben.

Die DGN gratuliert Herrn PD Dr. Martin Freesmeyer sehr herzlich zu dieser Auszeichnung.

VERANTWORTLICH FÜR DEN INHALT

Deutsche Gesellschaft für Nuklearmedizin e. V. (DGN)

Prof. Dr. Bernd Joachim Krause (Präsident)

Nikolaistr. 29, 37073 Göttingen

E-Mail: office@nuklearmedizin.de

\section{Schriftführer:}

Prof. Dr. Peter Bartenstein

E-Mail: office@nuklearmedizin.de

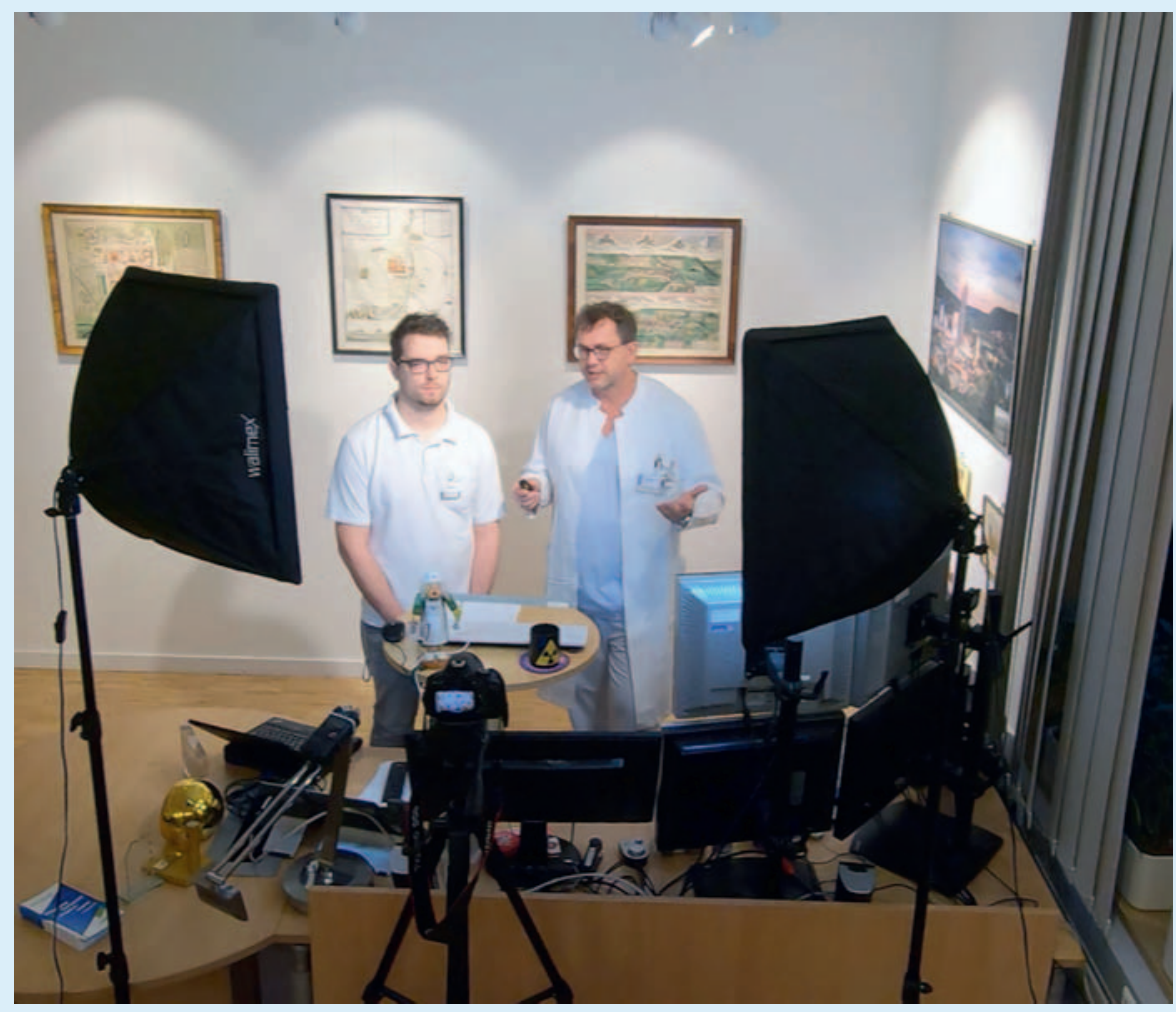

Quelle: UKJ/C. Kühnel.

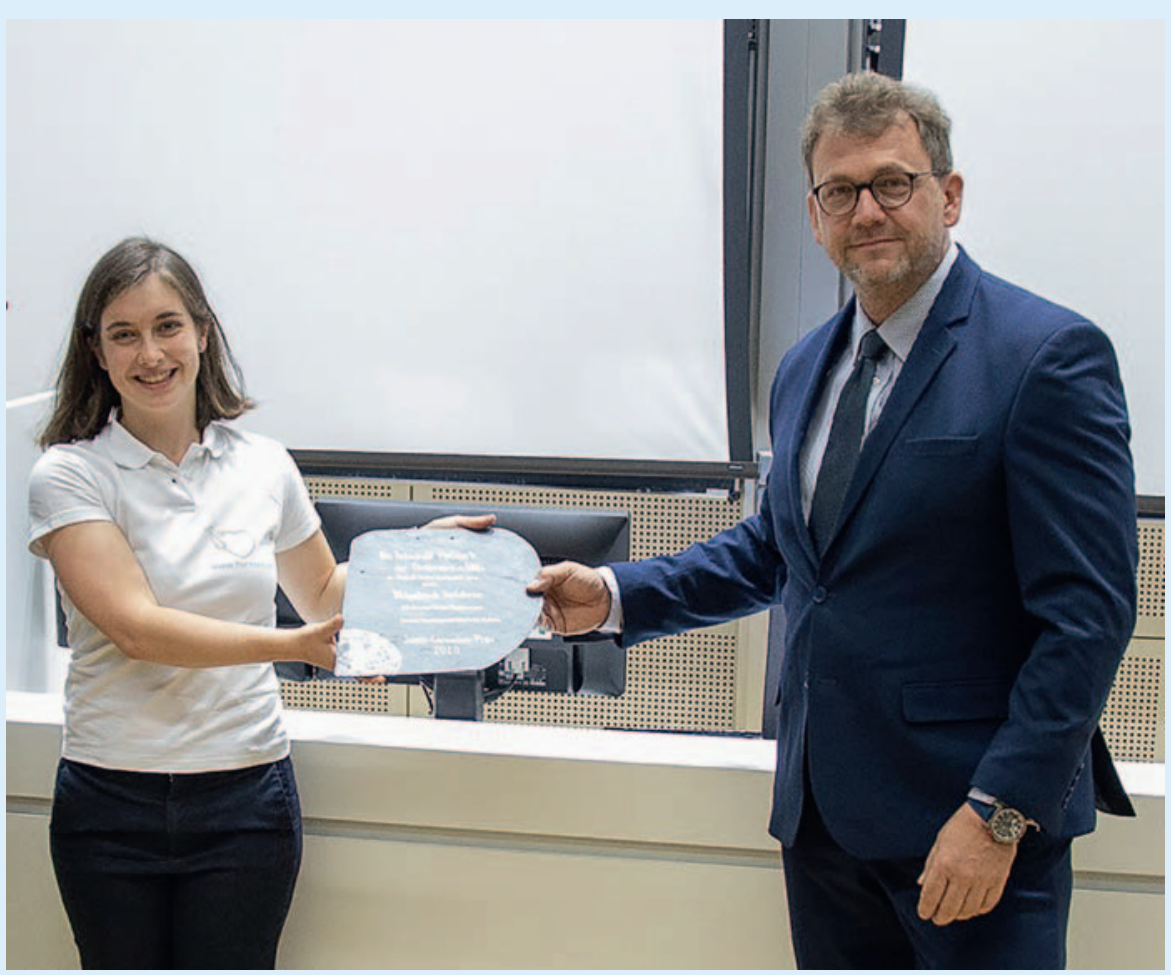

Quelle: UKJ/C. Ebert. 